\title{
Detection of Inflammatory Circulating Endothelial Cells Using Human Umbilical Vein Endothelial Cells Detached from Culture Dishes by Tumor Necrosis Factor-alpha as Control Cells
}

Junpei Tochikubo1,2, Naoyuki Matsuda1*, Yoshimi Ota1, Tomoko Higashi1, Yudai Takatani1, Masato Inaba1, Yushi Adachi1 and Norihiko Shiiya2

${ }^{1}$ Department of Emergency and Critical Care Medicine, Nagoya University Graduate School of Medicine, Nagoya, Japan

${ }^{2}$ First Department of Surgery, Hamamatsu University School of Medicine, Hamamatsu, Japan

\begin{abstract}
Background: Systematic inflammatory response syndrome (SIRS) with disseminated intravascular coagulation (DIC) is a severe disorder in critically ill patients and closely related to progression of vascular endothelial injury. Early diagnosis is required to prevent the progression of organ dysfunction. Circulating endothelial cells (CECs) might increase in vascular endothelial injury and play an important role in DIC diagnosis. However, the CEC detection method has not been standardized. This study aimed to establish a method for CEC detection in a critical care setting. We used human umbilical vein endothelial cells (HUVECs) detached from culture dishes by tumor necrosis factor-alpha (TNF- $\alpha$ ) as control cells for CECs.
\end{abstract}

Methods: Cultured HUVECs were incubated in medium with TNF- $\alpha(100 \mathrm{ng} / \mathrm{mL})$, and cells detached from culture dishes after $24 \mathrm{~h}$ were used as TNF-HUVECs. Cell surface molecules of normal HUVECs, TNF-HUVECs, and blood cells were analyzed using flow cytometry $(F C)$ to search for appropriate markers for detecting CECs. Normal HUVECs and TNF-HUVECs were added to the blood and detected using FC and the immunobead method (IB) for comparing two methods. CECs were measured in healthy volunteers and intensive care unit (ICU) patients using FC.

Results: CD146 and CD105 were highly expressed in HUVECs and superior for separation of UVECs from whole blood cells. Mean detection rates of normal HUVECs were $75 \%$ in FC and $82 \%$ in IB. However, mean detection rates of TNF-HUVECs were $64 \%$ in FC and $27 \%$ in IB $(p<0.05)$. Mean CEC counts from 20 healthy volunteers and $16 \mathrm{ICU}$ patients were $2.8 \mathrm{cells} / \mathrm{mL}$ and $4.3 \mathrm{cells} / \mathrm{mL}$, respectively. In one ICU patient with SIRS-induced DIC, CECs were elevated by 49 cells $/ \mathrm{mL}$.

Conclusion: CD146 and CD105 are suitable for detecting endothelial cells from blood. FC is superior to IB for detecting endothelial cells in severe inflammatory states.

Keywords: Circulating endothelial cells; Human umbilical vein endothelial cells; Tumor necrosis factor-alpha; Control cells; Flow cytometry; Vascular endothelial injury; Systematic inflammatory response syndrome; Disseminated intravascular coagulation; Intensive care unit patients; Disseminated intravascular coagulation; Intensive care unit patients

Abbreviations: SIRS: Systematic Inflammatory Response Syndrome; DIC: Disseminated Intravascular Coagulation; CECs: Circulating Endothelial Cells; HUVECs: Human Umbilical Vein Endothelial Cells; TNF- $\alpha$ : Tumor Necrosis Factor-alpha; FC: Flow Cytometry; IB: Immunobead Method; ICU: Intensive Care Unit; UEA1: Ulex Europaeus Agglutinin 1; RT: room temperature; 7-AAD: 7-Aminoactinomycin D; PBS: Phosphate Buffered Saline; PE: Phycoerythrin; APC: Allophycocyanin; FITC: Fluorescein Isothiocyanate; FSC: Forward Scatter; SSC: Side Scatter; SOFA: System Organ Failure Assessment

\section{Introduction}

Circulating endothelial cells (CECs) are mature vascular endothelial cells released from vascular beds into the blood. The CEC count is increased by vascular endothelial injury in systemic vascular inflammation and many vascular diseases, including myocardial infarction, vasculitis, and cancer [1-6]. CEC count is correlated with survival in coronary artery disease [2]. Further, in antineutrophil cytoplasmic antibody-associated vasculitis, inflammatory activity and CEC levels are correlated [3]. Accurate quantification of CECs would allow evaluation of the pathophysiological progression of vascular endothelial injury.

Critically ill patients tend to have serious inflammation such as systemic inflammatory response syndrome (SIRS) [7]. SIRS leads to SIRS-associated coagulopathy and disseminated intravascular coagulation (DIC), which is closely related to progression of vascular endothelial injury [8,9]. Early and appropriate diagnosis of DIC in critically ill patients with SIRS is required to avoid multiple organ dysfunction. The establishment of a method for CEC detection could play an important role in preventing severe DIC and multiple organ dysfunctions.

*Corresponding author: Naoyuki Matsuda, Department of Emergency and Critica Care Medicine, Nagoya University Graduate School of Medicine, Nagoya, Japan, Tel: 052-747-6389; E-mail: nmatsuda@med.nagoya-u.ac.jp

Received October 28, 2014; Accepted January 15, 2015; Published January 20, 2015

Citation: Tochikubo J, Matsuda N, Ota Y, Higashi T, Takatani Y, et al. (2015) Detection of Inflammatory Circulating Endothelial Cells Using Human Umbilical Vein Endothelial Cells Detached from Culture Dishes by Tumor Necrosis Factor-alpha as Control Cells. Cardiol Pharmacol 4: 129. doi:10.4172/2329-6607.1000129

Copyright: (C) 2015 Tochikubo $\mathrm{J}$ et al. This is an open-access article distributed under the terms of the Creative Commons Attribution License, which permits unrestricted use, distribution, and reproduction in any medium, provided the origina author and source are credited. 
Citation: Tochikubo J, Matsuda N, Ota Y, Higashi T, Takatani Y, et al. (2015) Detection of Inflammatory Circulating Endothelial Cells Using Human Umbilical Vein Endothelial Cells Detached from Culture Dishes by Tumor Necrosis Factor-alpha as Control Cells. Cardiol Pharmacol 3: 129. doi:10.4172/2329-6607.1000129

Page 2 of 8

Previously reported methods for CEC detection were controversial. Measurements of CECs in healthy subjects show large differences [2,46,10-17]. An appropriate positive control needs to be used for accurate measurement of CECs. Tumor necrosis factor-alpha (TNF- $\alpha$ ) is one of the major proinflammatory cytokines and contributes to endothelial injury in SIRS. Therefore, endothelial cells detached by TNF- $\alpha$ might be an appropriate positive control for CECs in critically ill patients with SIRS-induced DIC.

This study aimed to establish a method for CEC detection in a critical care setting. We used human umbilical vein endothelial cells (HUVECs) detached from culture dishes by TNF- $\alpha$ as control cells control cells for CECs.

\section{Materials and Methods}

\section{Ethical approval}

All study protocols were approved by the Institutional Review Board of Nagoya University Hospital (Approval Number 2012-0336). All participants provided written informed consent. The HUVECs were obtained from a commercial source (200-05n; Cell Applications Inc, San Diego, USA). All experiments were performed at the Nagoya University Graduate School of Medicine (Nagoya, Japan).

\section{Preparation of normal-HUVECs and TNF-HUVECs}

HUVECs were incubated with vascular endothelial growth medium (EGM-2; Lonza, Basel, Switzerland) in culture dishes at $37^{\circ} \mathrm{C}$ and $5 \% \mathrm{CO}_{2}$ until they reached approximately $50 \%$ confluence. TNF- $\alpha$ (100 ng/mL; Wako, Osaka, Japan) was administered and the detached cells, after $24 \mathrm{~h}$, were used as TNF-HUVECs.

To generate control cells against TNF-HUVECs, HUVECs were incubated in EGM-2 without TNF- $\alpha$. The adherent cells were trypsinized after $24 \mathrm{~h}$ and used as Normal-HUVECs.

\section{Analysis of cell surface molecules of Normal-HUVECs, TNF- HUVECs, and blood cells}

One hundred microliters of cell suspensions $\left(1 \times 10^{7}\right.$ cells $\left./ \mathrm{mL}\right)$ of Norma-HUVECs, TNF-HUVECs, and blood cells from a healthy volunteer were incubated with fluorescence-conjugated ulex europaeus agglutinin 1 (UEA1) and antibodies against CD146, CD105, CD31, CD309, CD34, CD45, and CD133 for $30 \mathrm{~min}$ at room temperature (RT). The samples were analyzed using a flow cytometer (FACSCanto 2; BD Biosciences, San Jose, USA). FlowJo software (Tree Star Inc., Ashland, USA) was used for data analysis. 7-Aminoactinomycin D (7-AAD) was used as a marker of dead cells. Normal-HUVECs and TNF-HUVECs labeled with endothelial markers (CD146, CD105, CD31, and UEA1) and Hoechst 33342 were examined on microscope slides with a confocal microscope (A1RMP, Nikon, Tokyo, Japan).

\section{Detection of normal-HUVECs and TNF-HUVECs in blood}

Blood was obtained from healthy volunteers with written consent. Normal-HUVECs and TNF-HUVECs were labeled with Hoechst 33342 and the cell concentrations were determined by counting the number of Hoechst-positive cells using a Nageotte chamber (Sunlead Glass Corp, Saitama, Japan) and a fluorescence microscope (BX51; Olympus, Tokyo, Japan). One hundred microliters of a suspension of Normal-HUVECs and TNF-HUVECs $\left(1 \times 10^{3}\right.$ cells $\left./ \mathrm{mL}\right)$ was added to blood and analyzed using flow cytometry (FC) and the immunobead method (IB). Normal-HUVECs and TNF-HUVECs were defined as

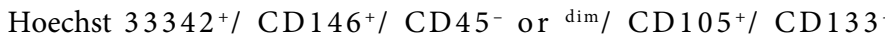

in FC and Hoechst $33342^{+} / \mathrm{CD}_{146^{+}} / \mathrm{UEA}^{+}$in IB. This procedure was performed eight times for each study.

\section{FC protocol}

One milliliter of blood was incubated with lysing solution (BD Biosciences, San Jose, USA) in a tube at RT for $15 \mathrm{~min}$. Ten milliliters of phosphate buffered saline (PBS) with $0.5 \%$ BSA and 2 mM EDTA was added, the tube was centrifuged at $400 \times \mathrm{g}$ for $5 \mathrm{~min}$, and the supernatant was then discarded. The sample was incubated at RT for $10 \mathrm{~min}$ with $200 \mu \mathrm{L}$ of blocking solution containing 10 $\mu \mathrm{L}$ of FcR blocking reagent (Miltenyi Biotec, Bergisch Gladbach, Germany) and $100 \mu \mathrm{L}$ of mouse serum (Sigma-Aldrich, St. Louis, USA). Then, it was mixed and incubated at RT for $30 \mathrm{~min}$ with $300 \mu \mathrm{L}$ of antibody solution containing $0.2 \mu \mathrm{L}$ of phycoerythrin (PE)-labeled anti-CD146, $4 \mu \mathrm{L}$ of allophycocyanin (APC)-labeled anti$\mathrm{CD} 105,4 \mu \mathrm{L}$ of PE-Vio770-labeled anti-CD45, $1 \mu \mathrm{L}$ of biotin-labeled anti-CD133, $1 \mu \mathrm{L}$ of fluorescein isothiocyanate (FITC)-labeled antibiotin, and $2 \mu \mathrm{L}$ of Hoechst 33342. The sample was dissolved in 1 $\mathrm{mL}$ of $2 \%$ paraformaldehyde following washing and analyzed using a FACSCanto 2 flow cytometer. TNF-HUVECs and blood cells of a healthy volunteer were used as controls in the FC gating strategy.

\section{IB protocol}

Four milliliters of blood was incubated with lysing solution in a tube at RT for $15 \mathrm{~min}$. Ten milliliters of buffer $(0.5 \%$ BSA and $2 \mathrm{mM}$ EDTA in PBS) was added, the tube was centrifuged at $400 \times \mathrm{g}$ for 5 $\mathrm{min}$, and the supernatant was discarded. The sample was dissolved in $1 \mathrm{~mL}$ of buffer, incubated with $10 \mu \mathrm{L}$ of $\mathrm{FcR}$ blocking reagent at 4 ${ }^{\circ} \mathrm{C}$ for $10 \mathrm{~min}$, and then incubated with $100 \mu \mathrm{L}$ of anti-CD146-coated beads in a rotating mixer at $4{ }^{\circ} \mathrm{C}$ for $30 \mathrm{~min}$. One milliliter of buffer was added, the tube was placed on a magnet (Magna-stand 8; Chisso, Tokyo, Japan), and the supernatant was discarded. The sample was incubated at $4^{\circ} \mathrm{C}$ for $30 \mathrm{~min}$ with $100 \mu \mathrm{L}$ of solution containing $10 \mu \mathrm{g}$ of FITC-conjugated UEA1 and $1 \mu \mathrm{g}$ of Hoechst 33342 . The sample was dissolved in $150 \mu \mathrm{L}$ of buffer following washing and examined using a Nageotte chamber and a fluorescence microscope. Anti-CD146-coated beads were obtained by incubating $1 \mu \mathrm{g}$ anti CD146 antibody and 25 $\mu \mathrm{L}$ of Dynabeads (Veritas, Oslo, Norway) in a rotating mixer at $4^{\circ} \mathrm{C}$ for at least $1 \mathrm{~h}$.

\section{Detection of CECs in healthy volunteers and ICU patients}

Blood was obtained from healthy volunteers and intensive care unit (ICU) patients within 24 hours (day 1), 48-72 hours (day 3), 96120 hours (day 5) and 168-192 hours (day 8) following ICU admission. The first $3 \mathrm{~mL}$ of blood was discarded and the next $5 \mathrm{~mL}$ was used. CECs were measured using FC and defined as Hoechst $33342^{+} /$ $\mathrm{CD} 146^{+} / \mathrm{CD} 45^{-}$or $\mathrm{dim} / \mathrm{CD} 105^{+} / \mathrm{CD} 133$.

\section{Antibodies and materials}

Antibodies and materials were obtained from the following suppliers: anti-CD146, PE-labeled anti-CD146, FITC-labeled antiCD105, and APC-labeled anti-CD45 from Abcam (Cambridge, UK); APC-labeled anti-CD105, PE-Vio770-labeled anti-CD45, biotinlabeled anti-CD133, FITC-labeled anti-biotin, PE-labeled anti-CD309, FITC-labeled anti-CD34, APC-labeled anti-CD133 from Miltenyi Biotec; FITC-labeled anti-CD31 and 7-AAD from Biolegend (San Diego, USA); FITC-conjugated UEA1 from Vector Laboratories (Burlingame, USA); and Hoechst 33342 from Dojindo (Kumamoto, Japan). 
Citation: Tochikubo J, Matsuda N, Ota Y, Higashi T, Takatani Y, et al. (2015) Detection of Inflammatory Circulating Endothelial Cells Using Human Umbilical Vein Endothelial Cells Detached from Culture Dishes by Tumor Necrosis Factor-alpha as Control Cells. Cardiol Pharmacol 3: 129. doi:10.4172/2329-6607.1000129

Page 3 of 8

\section{Statistical analysis}

Statistical comparisons of detection rates of Normal-HUVECs and TNF-HUVECs between FC and IB were done using Bland-Altman analysis. Differences in CEC counts of healthy volunteers and ICU patients were evaluated using the Student's t-test. P-values $<0.05$ were considered statistically significant.

\section{Results}

\section{Sensitivity of endothelial cell markers in HUVECs}

CD146, CD105, CD31, and UEA1 had higher sensitivity than the other markers in HUVECs, as shown in Figure 1 and Supplementary Table 1.

\section{Specificity of endothelial cell markers in HUVECs}

CD146 and CD105 were superior to CD31 and UEA1 for separation of HUVECs from whole blood cells, as shown in Figure 2 and Supplementary Table 2.

\section{Characteristics of TNF-HUVECs}

Almost TNF-HUVECs were dead cells (7-AAD positive, Figure 3C) and had heterogeneous cell surface molecules and nuclei fragmentation, as shown in Figure 3B. Antigenicities of CD146 and CD105 were decreased in TNF-HUVECs as compared to that in Normal-HUVECs, as shown in Figure 3C and Supplementary Table 3.

\section{FC gating strategy for detection of CECs}

Almost all TNF-HUVECs were detected, and blood cells were excluded by the gating strategy, as shown in Figure 4.

\section{Comparison of FC and IB}

The detection rate of Normal-HUVECs was not significantly different between by FC and by IB. However, the detection rate of TNF-HUVECs was significantly lower by IB than by FC, as shown in Table 1.

\section{Detection of CECs in healthy volunteers}

Twenty healthy volunteers (12 men and 8 women) participated in this study. The mean age was 38 years (range, 25-51 years). The mean CEC count was 2.8 cells $/ \mathrm{mL}$ (range, $0-11$ cells $/ \mathrm{mL}$ ).

\section{Detection of CECs in ICU patients}

Sixteen ICU patients ( 11 men and 5 women) participated in the study. These patients had no cancer. The mean age was 72 years (range, 57-90 years). The main causes of ICU admission were the following disorders: acute heart failure (5), sepsis (4), acute pancreatitis (2), acute aortic dissection (1), acute myocardial infarction (1), cerebral infraction (1), diabetic ketoacidosis (1), and femur fractures (1). The median Japanese Association for Acute Medicine DIC scores and System Organ Failure Assessment (SOFA) scores [8] of 16 ICU patients were 2.0 (range, 1-8) and 6.0 (range, 2-18), respectively. The mean CEC count was 4.3 cells $/ \mathrm{mL}$ (range, $0-49$ cells $/ \mathrm{mL}$ ). There was no significant difference between ICU patients and healthy volunteers
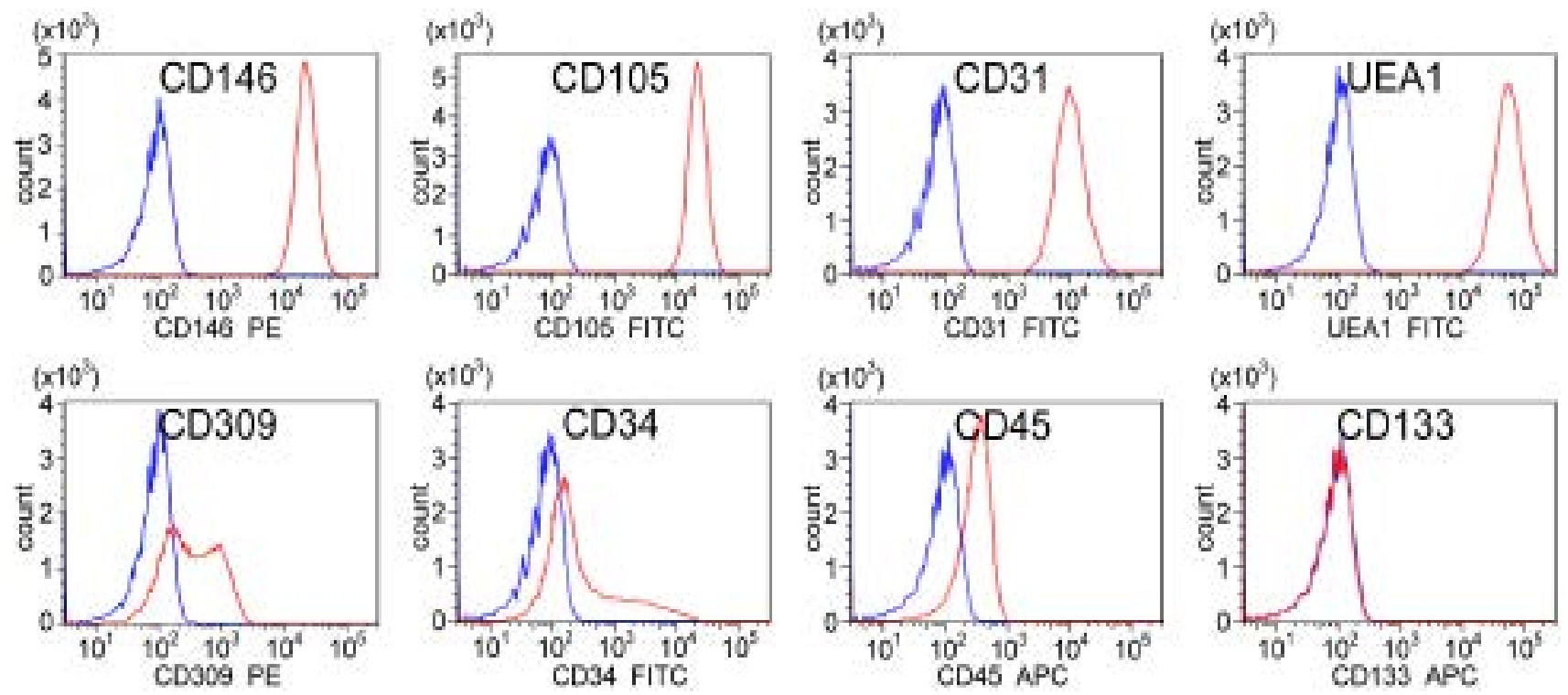

Figure 1: Search for specific markers of HUVECs.FC shows expression of specific markers in HUVECs. Red histograms show signals of specific markers. Blue histograms show signals of isotype controls. The positive signal intensities of CD146, CD105, CD31, and UEA1 were very high.

FC

\begin{tabular}{|l|l|l|l|l|}
\hline Normal-HUVECs & $75 \%$ & $(62-89 \%)$ & $82 \%$ & $(72-106 \%)$ \\
\hline TNF-HUVECs & $64 \%$ & $(44-79 \%)$ & $27 \%{ }^{*}$ & $(22-31 \%)$ \\
\hline
\end{tabular}

Data shows the mean (range) of detection rates of Normal-HUVECs and TNF-HUVECs in blood by FC and IB. * $P<0.05$.

Table 1. Detection rates of Normal-HUVECs and TNF-HUVECs. 
Citation: Tochikubo J, Matsuda N, Ota Y, Higashi T, Takatani Y, et al. (2015) Detection of Inflammatory Circulating Endothelial Cells Using Human Umbilical Vein Endothelial Cells Detached from Culture Dishes by Tumor Necrosis Factor-alpha as Control Cells. Cardiol Pharmacol 3: 129. doi:10.4172/2329-6607.1000129

Page 4 of 8

\begin{tabular}{|c|c|c|c|c|}
\hline & Day 1 & Day 3 & Day 5 & Day 8 \\
\hline CECs (cells/mL) & 49 & 13 & 12 & 3 \\
\hline $\begin{array}{l}\text { Japanese Association for Acute } \\
\text { Medicine }\end{array}$ & 8 & 8 & 7 & 7 \\
\hline \multicolumn{5}{|l|}{ DIC scores } \\
\hline SIRS criteria & 3 & 3 & 2 & 0 \\
\hline PLT (count/ $/ \mu \mathrm{L})$ & 5000 & 26000 & 26000 & 33000 \\
\hline PT-INR & 1.55 & 1.48 & 1.38 & 1.30 \\
\hline $\mathrm{FDP}(\mu \mathrm{g} / \mathrm{mL})$ & 72.1 & 89.1 & 34.5 & 36.0 \\
\hline SOFA scores & 15 & 16 & 13 & 9 \\
\hline Respiration & 4 & 3 & 2 & 2 \\
\hline Coagulation & 4 & 3 & 3 & 3 \\
\hline Liver & 1 & 2 & 1 & 0 \\
\hline Cardiovascular & 3 & 3 & 3 & 1 \\
\hline Neurogical & 1 & 2 & 1 & 1 \\
\hline Renal & 2 & 3 & 3 & 2 \\
\hline
\end{tabular}

Table 2. CEC counts and clinical data for an ICU patient.
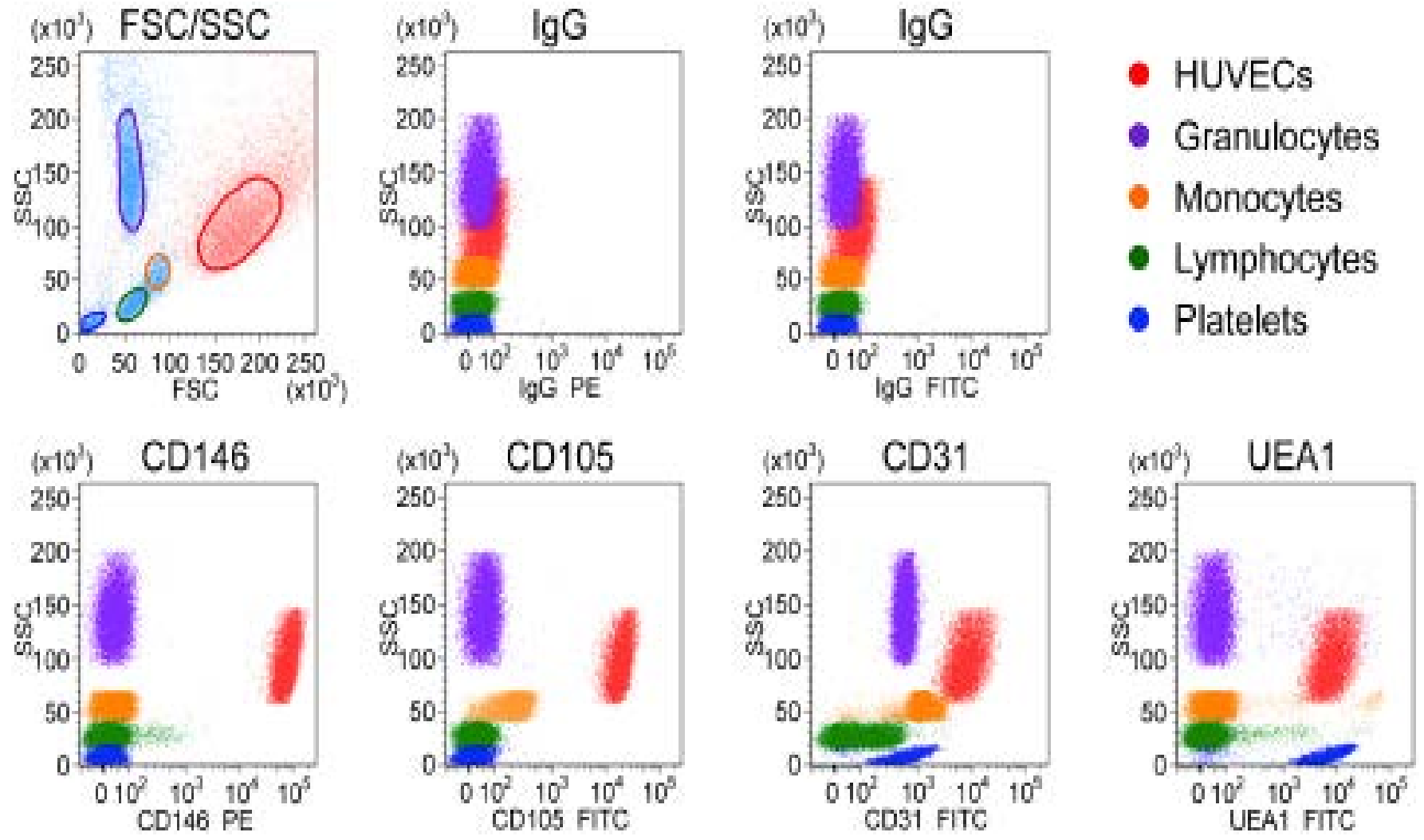

Figure 2: Separation of HUVECs from blood using endothelial markers. FC shows expression of specific markers in HUVECs and blood cells. Types of blood cells (light blue dots) and HUVECs (light red dots) were separated by FSC/SSC gating. IgG was used as a negative control. CD146 and CD105 were hardly expressed in blood cells. 
Citation: Tochikubo J, Matsuda N, Ota Y, Higashi T, Takatani Y, et al. (2015) Detection of Inflammatory Circulating Endothelial Cells Using Human Umbilical Vein Endothelial Cells Detached from Culture Dishes by Tumor Necrosis Factor-alpha as Control Cells. Cardiol Pharmacol 3: 129. doi:10.4172/2329-6607.1000129

A

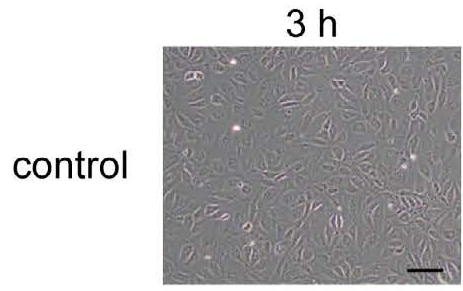

TNF- $\alpha$

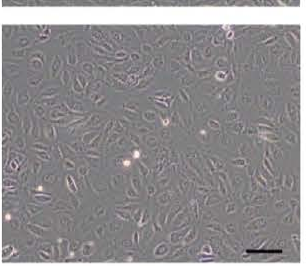

$6 \mathrm{~h}$
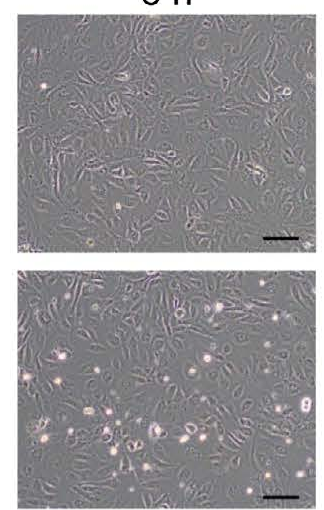

$12 \mathrm{~h}$
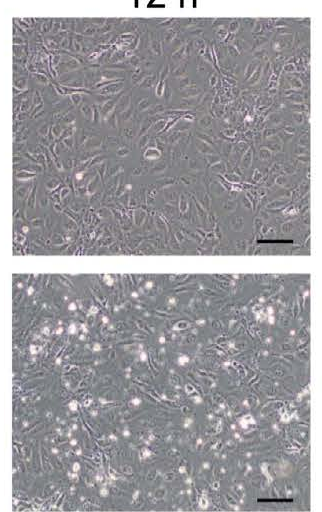

$24 \mathrm{~h}$
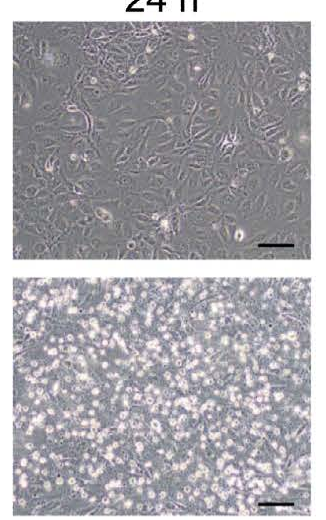

B
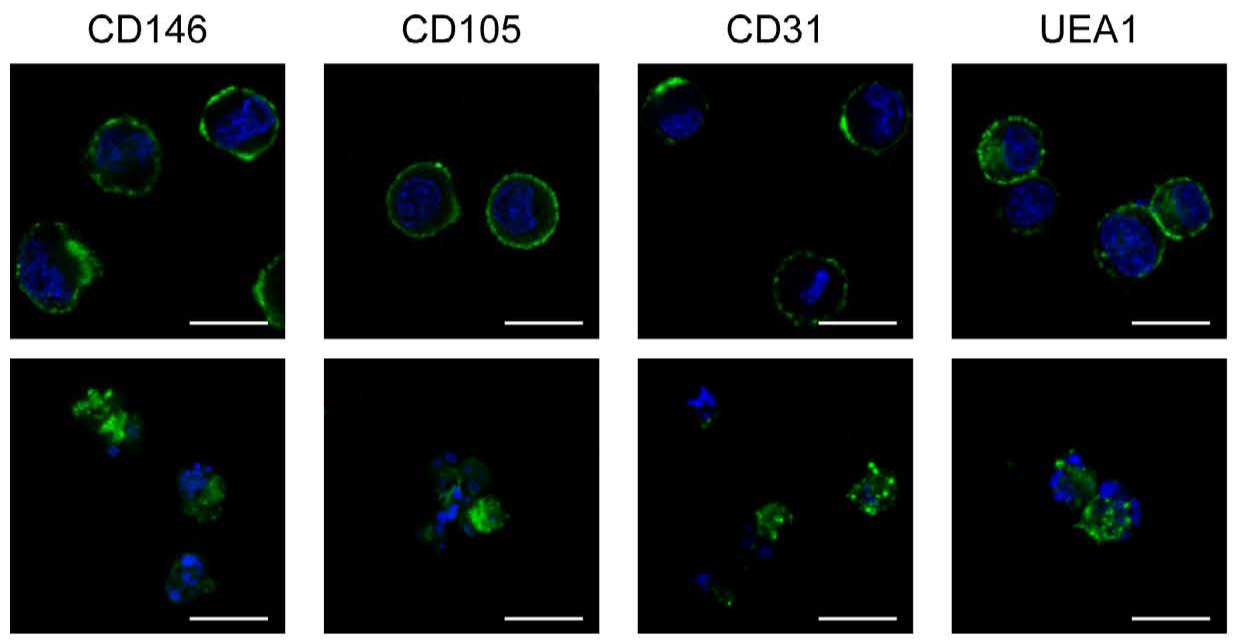
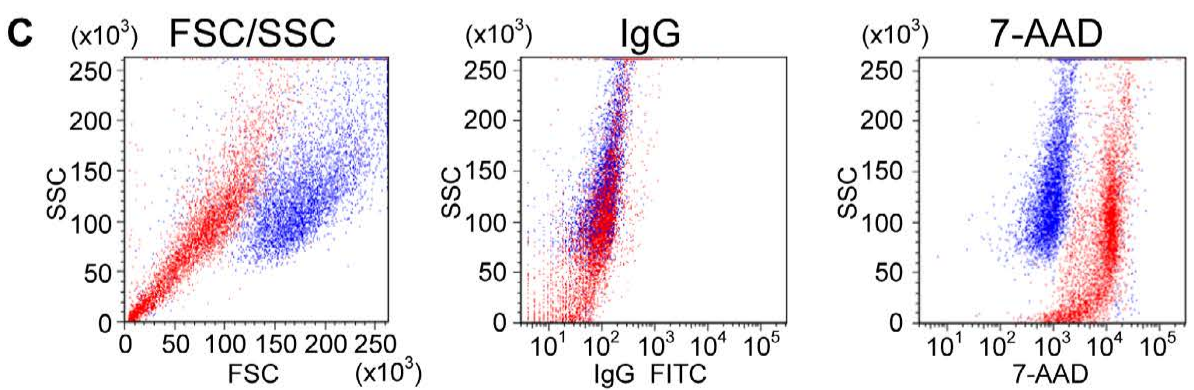

- Normal-HUVECs
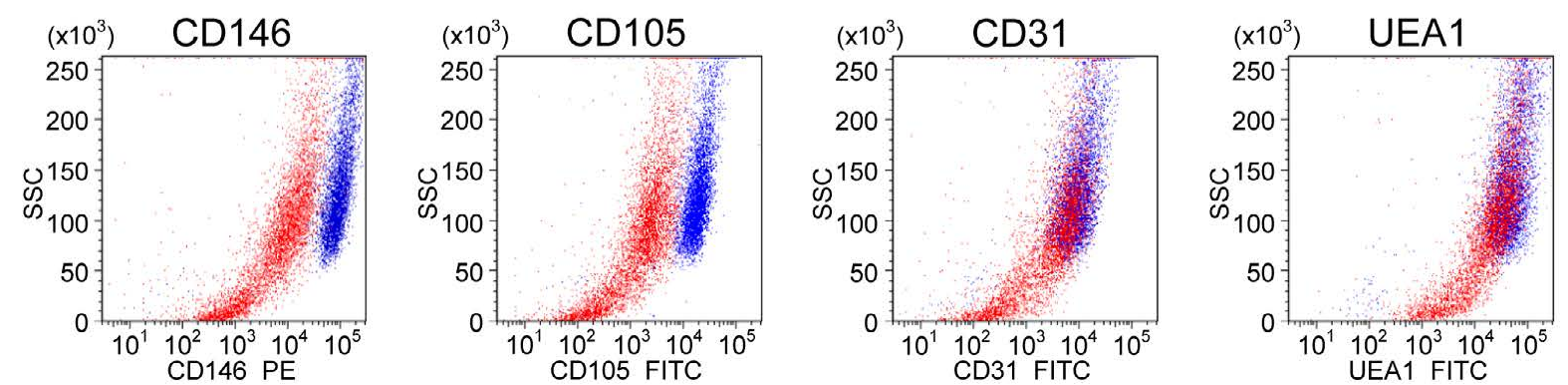

Figure 3: Characteristics of TNF-HUVECs. (A) Phase-contrast micrographs of cultured HUVECs show that detached cells in a culture dish are greatly increased at 12-24 h after administration of $100 \mathrm{ng} / \mathrm{mL}$ of TNF- $\alpha$. Scale bar indicates $100 \mu \mathrm{m}$. (B) Confocal micrographs show cell surface molecules and nuclei in NormalHUVECs and TNF-HUVECs. Blue indicates nuclei stained with Hoechst. Green indicates endothelial markers labeled with FITC. Scale bar indicates 20 um. (C) FC shows comparison of Normal-HUVECs and TNF-HUVECs. Signal intensity of CD146 and CD105 was much lower in TNF-HUVECs than in Normal-HUVECs. Most TNF-HUVECs were positive for 7-AAD. 
Citation: Tochikubo J, Matsuda N, Ota Y, Higashi T, Takatani Y, et al. (2015) Detection of Inflammatory Circulating Endothelial Cells Using Human Umbilical Vein Endothelial Cells Detached from Culture Dishes by Tumor Necrosis Factor-alpha as Control Cells. Cardiol Pharmacol 3: 129. doi:10.4172/2329-6607.1000129

Page 6 of 8

in CEC counts. However, in one ICU patient, CECs were elevated. The patient was a 71-year-old man who developed a type A aortic dissection and underwent total aortic replacement. SIRS-induced DIC was caused by surgical site infection on the 18th day following

surgery. He was admitted to the ICU on the 25th day. Antibiotics and recombinant human soluble thrombomodulin were administrated against the infection and DIC. CECs gradually decreased with the improvement of Japanese Association for Acute Medicine DIC scores and SOFA scores in table 2. He was discharged from the ICU on the 10th day following admission.

\section{Discussion}

CECs have been defined as mature vascular endothelial cells released into the blood in several types of vascular endothelial injury [1], but it is not known if this definition is reliable for critical illness with SIRS. In a septic mouse, it was observed that vascular endothelial cells proceeded to apoptosis and detached from the vascular beds [18], which indicated that the detached CECs would not be normal in SIRS. Therefore, control cells for CECs should not be normal endothelial cells in patients with SIRS.

TNF- $\alpha$ is known as a major proinflammatory cytokine and a potent inducer of endothelial cell injury. In this study, TNF- $\alpha$ could induce detachment of HUVECs from the culture dish. These detached cells would be suitable for use as a positive control for CECs in critically ill patients with SIRS.

We searched for appropriate markers for detecting CECs. CD34 [11-15], CD31 [6,11,16-17], and UEA1 [2,3,10,13] had been widely used in previous studies for detecting CECs because of the expression in pan-endothelial cells. However, the expression of CD34 was actually low in HUVECs, as shown in Figure 1 and Supplementary Table 1. CD31 was expressed on platelets and leukocytes in addition to HUVECs, as shown in Figure 2 and Supplementary Table 2. Therefore, discriminating CECs from platelets [19] and monocytes [20,21] might be difficult using CD31. UEA1 had strong signal intensity in platelets, which was identical to that in HUVECs, as shown in Figure 2. We concluded that CD146 and CD105 had high sensitivity and the highest specificity to HUVECs.

We demonstrated that the detection rate of TNF-HUVECs was lower by IB than by FC, although that of Normal-HUVECs was similar by IB and by FC, as shown in Table 1 . This indicates that IB and FC are equivalent in the detection of normal endothelial cells but FC is superior to IB in the detection of endothelial cells in severe inflammatory states, such as TNF-HUVECs. It is reasonable to use FC for detecting CECs of SIRS patients because CECs are endothelial cells detached from vascular beds by severe inflammation like TNFHUVECs. The low detection rate of TNF-HUVECs in IB would be because of the low antigenicities of CD146 in TNF-HUVECs, as shown in Figure 3C and Supplementary Table 3. The antigenicities of CD146 in CECs of an ICU patient were as low as TNF-HUVECs, as shown in Figure 5 and Supplementary Table 4. For detecting cells with low antigenicities, it is important to combine fluorescent dyes with high signal-to-noise ratio (PE, APC) with endothelial markers and to adjust the range of the gating in FC, as shown in Figure 4.

We have two additional recommendations for detecting inflammatory CECs. The first is that forward scatter (FSC) and side scatter (SSC) gating should not be used. The range of SSC of CECs was thought to be identical to that of mononuclear cells $[7,11,13,15,17]$, but it was actually more varied, as shown in Figure 5. Furthermore, it is known that about 25\% of CECs in patients with myocardial infarction have multiple nuclei [22], which indicate that the range of FSC and SSC of CECs is very wide. It is not reasonable to determine the ranges of FSC and SSC for the detection of CECs. Our second recommendation is that positive and negative markers for CECs should be combined and a pentagon polygon gate be used in each gating, as shown in Figure 4. False positive CECs might be induced by high intrinsic fluorescent intensity if two positive markers were combined and a square gate was used.

We detected the CECs in human blood under the conditions described above. In our study, a mean value of 2.8 cells $/ \mathrm{mL}$ of CECs was noted for healthy volunteers. On the other side, previous studies reported values between 140 and 13,400 cells/mL [6,15-17]. They could include false positive blood cells because of the use of CD31 as the marker of CECs, as mentioned above.

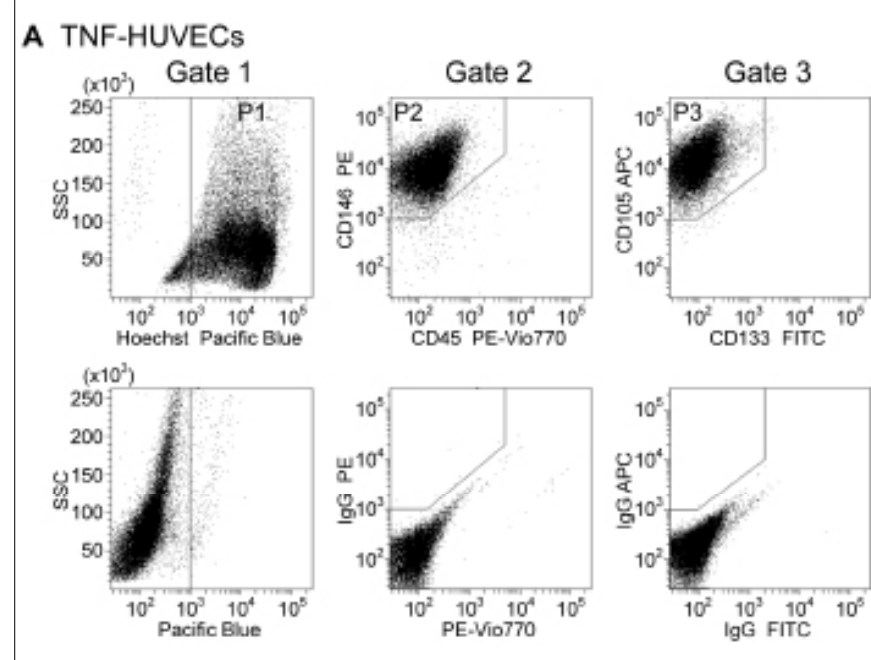

\section{B Blood cells}
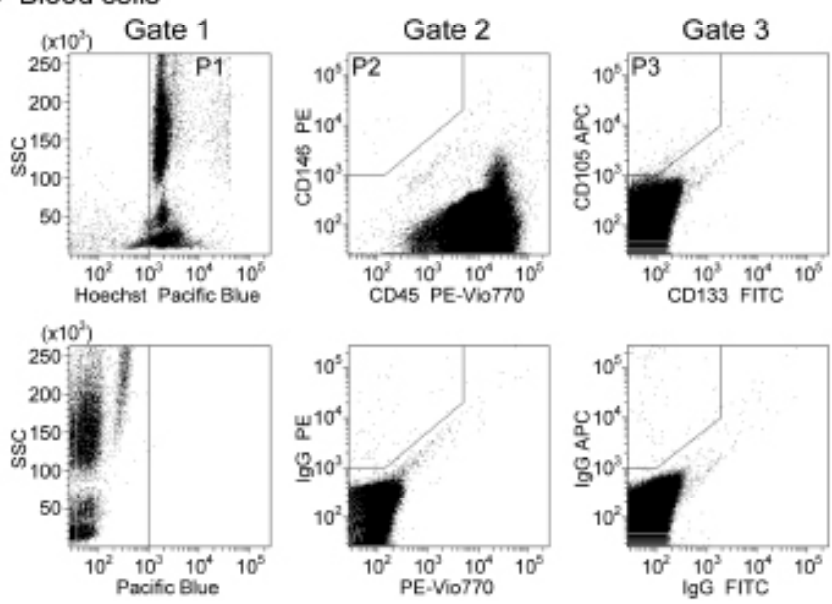

Figure 4: FC gating strategy for CEC detection. Histograms show FC gating strategy. TNF-HUVECs (A) and blood cells (B) were analyzed. Nucleated cells (P1: Hoechst+) were separated at gate 1. Pan-endothelial cells (P2: CD146+/CD45- or dim) were separated from the nucleated cells at gate 2 . Mature endothelial cells (P3: CD105+/CD133-) were separated from the panendothelial cells at gate 3 . IgG was the negative control for specific markers. 
Citation: Tochikubo J, Matsuda N, Ota Y, Higashi T, Takatani Y, et al. (2015) Detection of Inflammatory Circulating Endothelial Cells Using Human Umbilical Vein Endothelial Cells Detached from Culture Dishes by Tumor Necrosis Factor-alpha as Control Cells. Cardiol Pharmacol 3: 129. doi:10.4172/2329-6607.1000129

\section{A ICU patient-CECs}
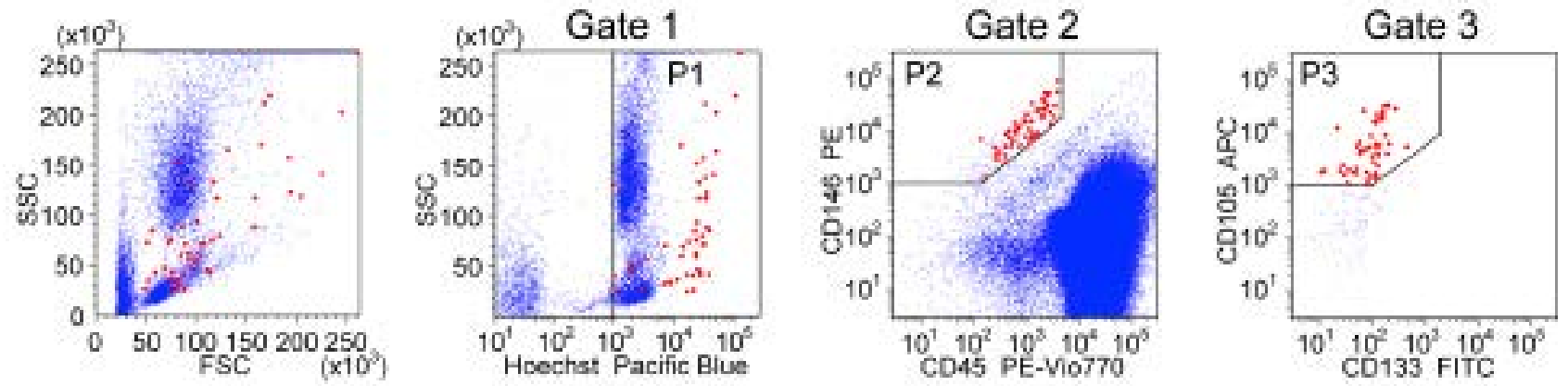

\section{B Normal-HUVECs}
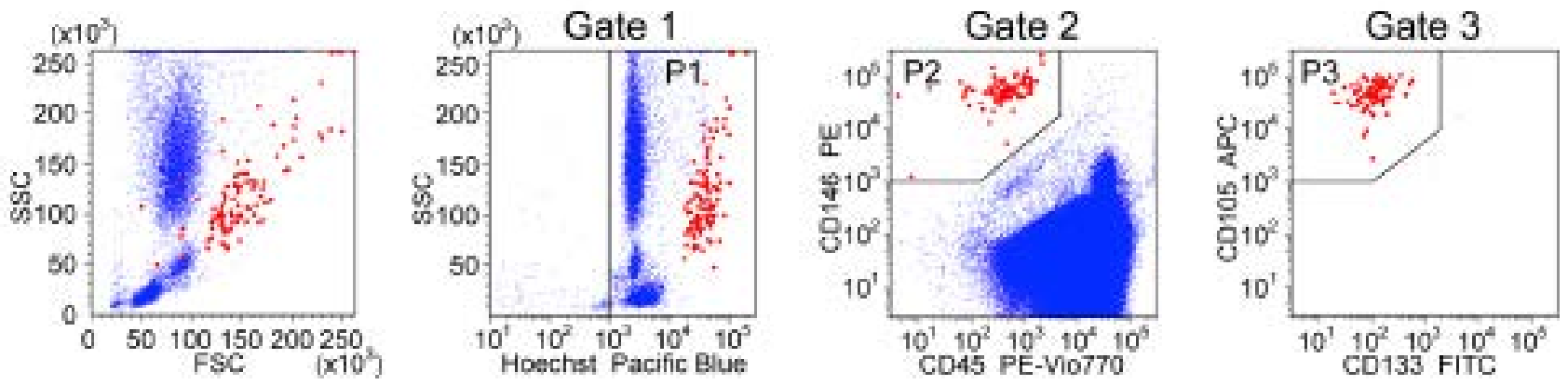

\section{TNF-HUVECs}
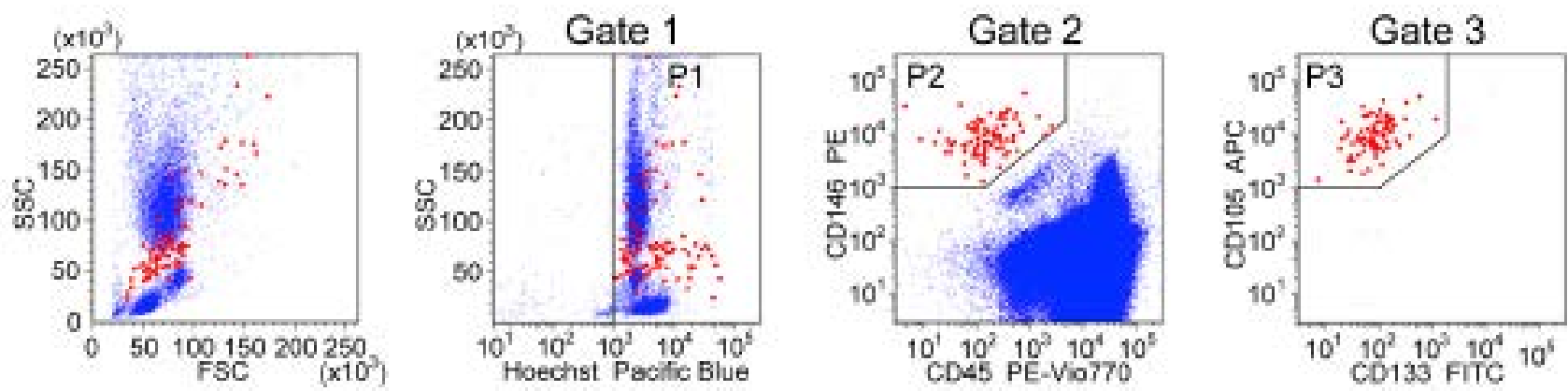

Figure 5: Characteristics of CECs of an ICU patient. Large red dots show CECs detected in an ICU patient (A), Normal-HUVECs (B), and TNF-HUVECs (C) in FC The signal intensity of CD146 and CD105 were lower in CECs and TNF-HUVECs than in Normal-HUVECs.

In one ICU patient, the number of CECs was significantly correlated with clinical severity, as shown in Table 2. CECs might play an important role as a clinical marker for severity of vascular endothelial injury in critically ill patients. In SIRS, endothelial cells are activated by inflammatory cytokines, such as TNF- $\alpha$, and produce von Willebrand factor and adhesion molecules. These are able to induce the attachment of neutrophils and platelets to endothelial cells [23]. If neutrophils are attached to CECs similarly, neutrophils-attached CECs may not be detected. However, the attachment of neutrophils to CECs was not found in healthy subjects and ICU patients using IB in our study. On the other hand, aggregation of neutrophils and platelets was found in ICU patients. Finally, FC using CD146, CD105, and CD45 Could be effective in excluding aggregated neutrophils and platelets in SIRS patient with DIC.
In conclusion, FC is superior to IB for detecting endothelial cells in severe inflammatory states in our protocol. TNF-HUVECs are effective control cells for detecting inflammatory CECs.

\section{Acknowledgments}

We are grateful to the staff at the Department of Emergency and Critical Care Medicine of Nagoya University Graduate School of Medicine for patient recruitment, and Mamoru Yamashita and Rie Ito at Bell Research Center for technical assistance.

\section{References}

1. Erdbruegger U, Haubitz M, Woywodt A (2006) Circulating endothelial cells: a novel marker of endothelial damage. Clin Chim Acta 373: 17-26.

2. Boos CJ, Balakrishnan B, Blann AD, Lip GY (2008) The relationship of circulating endothelial cells to plasma indices of endothelial damage/dysfunction and apoptosis in acute coronary syndromes: implications for prognosis. J Thromb Haemost 6: 1841-1850. 
Citation: Tochikubo J, Matsuda N, Ota Y, Higashi T, Takatani Y, et al. (2015) Detection of Inflammatory Circulating Endothelial Cells Using Human Umbilical Vein Endothelial Cells Detached from Culture Dishes by Tumor Necrosis Factor-alpha as Control Cells. Cardiol Pharmacol 3: 129. doi:10.4172/2329-6607.1000129

Page 8 of 8

3. de Groot K, Goldberg C, Bahlmann FH, Woywodt A, Haller H, et al. (2007) Vascular endothelial damage and repair in antineutrophil cytoplasmic antibodyassociated vasculitis. Arthritis Rheum 56: 3847-3853.

4. Schlichting DE, Waxman AB, O'Brien LA, Wang T, Naum CC, et al. (2011) Circulating endothelial and endothelial progenitor cells in patients with severe sepsis. Microvasc Res 81: 216-221.

5. Woywodt A, Streiber F, de Groot K, Regelsberger H, Haller H, et al. (2003) Circulating endothelial cells as markers for ANCA-associated small-vesse vasculitis. Lancet 361: 206-210.

6. Mancuso P, Antoniotti P, Quarna J, Calleri A, Rabascio C, et al. (2009) Validation of a standardized method for enumerating circulating endothelia cells and progenitors: flow cytometry and molecular and ultrastructural analyses. Clin Cancer Res 15: 267-273.

7. Bone RC, Balk RA, Cerra FB, Dellinger RP, Fein AM, et al. (1992) Definitions for sepsis and organ failure and guidelines for the use of innovative therapies in sepsis. The ACCP/SCCM Consensus Conference Committee. American College of Chest Physicians/Society of Critical Care Medicine. Chest 101: 1644-1655.

8. Gando S, Iba T, Eguchi Y, Ohtomo Y, Okamoto K, et al. (2006) A multicenter, prospective validation of disseminated intravascular coagulation diagnostic criteria for critically ill patients: comparing current criteria. Crit Care Med 34: 625-631.

9. Levi M (2007) Disseminated intravascular coagulation. Crit Care Med 35: 2191 2195.

10. Woywodt A, Blann AD, Kirsch T, Erdbruegger U, Banzet N, et al. (2006) Isolation and enumeration of circulating endothelial cells by immunomagnetic isolation: proposal of a definition and a consensus protocol. J Thromb Haemos 4: 671-677.

11. Duda DG, Cohen KS, Scadden DT, Jain RK (2007) A protocol for phenotypic detection and enumeration of circulating endothelial cells and circulating progenitor cells in human blood. Nat Protoc 2: 805-810.

12. Kraan J, Strijbos MH, Sieuwerts AM, Foekens JA, den Bakker MA, et al. (2012) A new approach for rapid and reliable enumeration of circulating endothelial cells in patients. J Thromb Haemost 10: 931-939.
13. Goon PK, Boos CJ, Stonelake PS, Blann AD, Lip GY (2006) Detection and quantification of mature circulating endothelial cells using flow cytometry and immunomagnetic beads: a methodological comparison. Thromb Haemost 96: 45-52.

14. Rowand JL, Martin G, Doyle GV, Miller MC, Pierce MS, et al. (2007) Endothelial cells in peripheral blood of healthy subjects and patients with metastatic carcinomas. Cytometry A 71: 105-113.

15. Mariucci S, Rovati B, Bencardino K, Manzoni M, Danova M (2010) Flow cytometric detection of circulating endothelial cells and endothelial progenitor cells in healthy subjects. Int J Lab Hematol 32: e40-48.

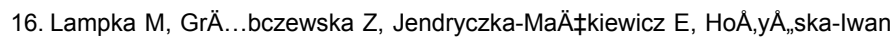
I, Sukiennik A, et al. (2010) Circulating endothelial cells in coronary artery disease. Kardiol Pol 68: 1100-1105.

17. Gritti G, Cortelezzi A, Bucciarelli P, Rezzonico F, Lonati S, et al. (2011) Circulating and progenitor endothelial cells are abnormal in patients with different types of von Willebrand disease and correlate with markers of angiogenesis. Am J Hematol 86: 650-656.

18. Matsuda N, Teramae H, Yamamoto S, Takano K, Takano Y, et al. (2010) Increased death receptor pathway of apoptotic signaling in septic mouse aorta: effect of systemic delivery of FADD siRNA. Am J Physiol Heart Circ Physiol 298: H92-101.

19. Strijbos MH, Kraan J, den Bakker MA, Lambrecht BN, Sleijfer S, et al. (2007) Cells meeting our immunophenotypic criteria of endothelial cells are large platelets. Cytometry B Clin Cytom 72: 86-93.

20. Yu HK, Lee HJ, Choi HN, Ahn JH, Choi JY, et al. (2013) Characterization of CD45-/CD31+/CD105+ circulating cells in the peripheral blood of patients with gynecologic malignancies. Clin Cancer Res 19: 5340-5350.

21. Damani S, Bacconi A, Libiger O, Chourasia AH, Serry R, et al. (2012) Characterization of circulating endothelial cells in acute myocardial infarction. Sci Transl Med 4: 126ra33.

22. Vincent JL, de Mendonca A, Cantraine F, Moreno R, Takala J, et al. (1998) Use of the SOFA score to assess the incidence of organ dysfunction/failure in intensive care units: results of a multicenter, prospective study. Working group on "sepsis-related problems" of the European Society of Intensive Care Medicine. Crit Care Med 26: 1793-1800.

23. Aird WC (2003) The role of the endothelium in severe sepsis and multiple organ dysfunction syndrome. Blood 101: 3765-3777. 